\title{
Design and sizing of a Hybrid PV-Wind-Grid System for Electric Vehicle Charging Platform
}

\author{
Kamal Anoune ${ }^{1,2^{*}}$, Mohsine Bouya ${ }^{1}$, Abdelali Astito $^{2}$, Abdellatif Ben Abdellah $^{1,3}$ \\ ${ }^{1}$ Laboratory of Renewable Energies and Advanced Materials (LERMA), International University of Rabat (UIR), Sala Al Jadida 11000, \\ Morocco.kamal.anoune@gmail.com. \\ ${ }^{2}$ Laboratory of Informatics, Systems \&Telecommunications (LIST), Faculty of Science and Technology of Tangier (FST) - Abdelmalek- \\ Essaadi University (UAE), Ziaten. BP: 416, Tangier, Morocco. \\ ${ }^{3}$ Laboratory of Engineering, Innovation and Management of Industrial Systems (LEIMIS), Faculty of Science and Technology of Tangier \\ (FST), Abdelmalek Essaâdi University (UAE), Ziaten. BP: 416, Tangier, Morocco.
}

\begin{abstract}
The recent technological advancement in the power electronics converters, control, and battery technology, allowed the enhancement of the use of the electric vehicle (EV) as a means of transportation, EV requires to be charged with an electrical grid which imposes an extra burden on the electrical supply during the peak demand duration. The use of renewable energy sources (RES) such as solar and wind remains as alternative sources to reduce this negative impact. The main interest of this work is integrating the RES in transportation systems through a smart grid system with a proposed design of a hybrid PV-Wind-Grid charging platform for EV.
\end{abstract}

Keywords: Electric Vehicle (EV); Vehicle-To-Grid (V2G), EV Charging Platform (EVCP), Hybrid PV-Wind-Grid System (HPWGS), Renewable Energy Sources (RES).

\section{Introduction}

The use of EV in the transportation sector is a promising vision aiming to solve the environmental issue and energy fossil crisis altogether. In this proposal, numerous governments in the worldwide have taken various initiatives to encourage the $\mathrm{EV}$ deployment. The environmental and economic are the major points of interest. Distinguished issues because of EV charging on the power grid mainly, a voltage drops, overloading of the grid, and finally harmonics and system losses. In spite of the fact that EV charging has stances challenges to the power grid operation, the EV deployment can bring a new view to the power grid subsequently EV can be considered as portable energy storage and can be powered from renewable energy such as solar and wind.

The renewable energy is used to charge the EV battery, the excess of this energy is injected into the grid, moreover EV battery can be utilized to power the grid using a bidirectional power converter, the energy exchange between the power grid and EV battery can be feasibly operated using the concept of vehicle to grid (V2G). It could provide various services to the hybrid power system, such as regulation of the power grid, rotating reserve, shaving of peak load, reactive power compensation and a realistic hub for renewable energy resources integration [1]. Several studies have analyzed

\footnotetext{
Kamal Anoune: kamal.anoune@gmail.com
}

the design, controls strategies and experimental test of the integration of an EV charging station as DC microgrid then studied the possibilities of the Vehicle to Grid (V2G) operation following different DC architecture [2]. Birnie et al. [3] investigated the effect of daytime recharging utilizing photovoltaic powering system situated at workplace parking lots. Nunes et al. [4] explored the potential complementarities of the energy excess during a daytime for renewable energy production for EV charging. Traube et al. [5] presented an experimental system where a bidirectional DC-DC electric vehicle charger is located between the highvoltage DC bus of a PV system and the EV battery. Chandra Mouli et al. [6] investigated and compared different system architecture for an EV-PV charger. Then they reviewed the power converter topologies that integrate EV and PV for bidirectional power capability for $\mathrm{V} 2 \mathrm{G}$ operation. Numerous studies are focused to present the importance of the use of a hybrid system as realistic power sources compared to the conventional fossil sources and to maximize the renewable power production [7], Anoune et al. [8] focused to size and integrate a PV-wind system to power process an industrial prototype using a deterministic approach. Providing a correct hybrid system configuration witch ensure powering load with a minimum cost of investment is the main objective of several research works. In this regard, Anoune et al. [9] presented a review work of current sizing and optimization technique used to size a 
hybrid PV wind system following different techniques, such as deterministic/stochastic, program tools and algorithms.

The main objectives of this paper is to size and integrate a hybrid PV-Wind-Grid system (HPWGS) to power a local prototype of EV charging platform (EVCP), and even to promote the use of the renewable energy sources (RES) such as a power source with the minimal energy exchange with the grid [7]. Moreover, an appropriate EVCP could provide a great flexibility to exchange the energy flow between RES, EV battery, and the grid. In this regard, a profile load of a slow charging station is adopted, then the campus of the international university of Rabat (UIR) Morocco is chosen as a location under study, next, a dynamic simulation of the meteorological data is presented, and finally, the long-term performance of the optimized system requirement is done through providing a dynamic simulation to illustrate the energy exchange between all components of EVCP of the chosen period.

\section{Hybrid PV-Wind-Grid System for EV Charging Platform}

An electric vehicle is powered exclusively by electricity through a charging station. The energy stored in its rechargeable batteries is used to ensure the mobility using an electric motor. The EV is more considerate to the environment than traditional cars when the energy produced by RES resources is used for their charging such as the current HPWGS under study.

The utilization of EV required another necessity to the help supports infrastructure to keep up their charging. EV must be equipped with the straightforward charger with an estimated input power between $3.3 \mathrm{~kW}$ to $3.7 \mathrm{~kW}$, this equivalent $16 \mathrm{~A}$ current with $230 \mathrm{VAC}$ such as power common in public uses. Another possibility is the use of 3 phase AC chargers with input power $22 \mathrm{~kW}$ equivalents to 32 A current with $400 \mathrm{VAC}$. These chargers may be used to charge an EV in slow charging mode. Although EV Chargers with input control up to $100 \mathrm{~kW}$ permitted to charge $\mathrm{EV}$ in the quick charging mode.

EV can be charged with using EVCP located in a specific zone, two types of charging speed can be identified.

- Fast Charging Station (FCS) is characterized by a quite short time $(15-30$ minutes $)$ for $\mathrm{EV}$ charging process and can reach to $50-80 \%$ of their maximum capacity. Several battery parameters should be identified and measured during the fast charging cycles to prevent the damage of the EV Batteries.

- Slow Charging Station (SCS) may take approximately between 5 to 8 hours. EV batteries can be charged up to $100 \%$ of their maximum capacity.
The use of smaller current during slow charging causes less technical problems and less damage to batteries. The SCS can present the real opportunity to be powered by the renewable energy system (RES) such as photovoltaic or wind turbine through an HPWGS with the maximum power reliability and the minimum cost of investment.

\section{Sizing the HPWGS}

In this work, the slow charging mode in EVCP is adopted. It can be used to charge EV batteries starting from $3.3 \mathrm{~kW}$ to $3.7 \mathrm{~kW}$ per hour. Referring to Nissan LEAF catalog [10], the 2011 Nissan Leaf has $24 \mathrm{kWh}$ capacity batteries and required at the least $3.3 \mathrm{~kW}$ per hour for its charging process. The EVCP required at the least an input power up to $3.7 \mathrm{~kW}$ with $230 \mathrm{~V}$ and should ensure between 5 to 8 hours of charge during the packing day in order to reach the EV batteries charge of $100 \%$.

Under the constraints of the maximum power reliability and the minimum system cost of EVCP, a sizingsimulation approach helps to determine the appropriate HPWGS requirement regarding three fundamental parameters:

- Meteorological input mainly the global irradiation, and the wind velocity of the chosen local implantation.

- The electrical demand profile, which explains the behavior of electrical power consumption.

- The specification of the hybrid system that includes the configuration and the technical specification of the desired equipment such as photovoltaic panels, wind turbine, and battery

The optimized configuration of HPWGS helps to power EVCP that used to charge the EV batteries. An appropriate developed program under TRNSYS (transient simulation package) [11] and Matlab are used to simulate the long-term electric energy output from a photovoltaic array and wind turbine. The campus of the International University of Rabat (UIR), Morocco (at latitude $33.980 \mathrm{~N}$, a longitude $6.709 \mathrm{~W}$ and an altitude of $75 \mathrm{~m}$ above sea level) will host the HPWGS under study.

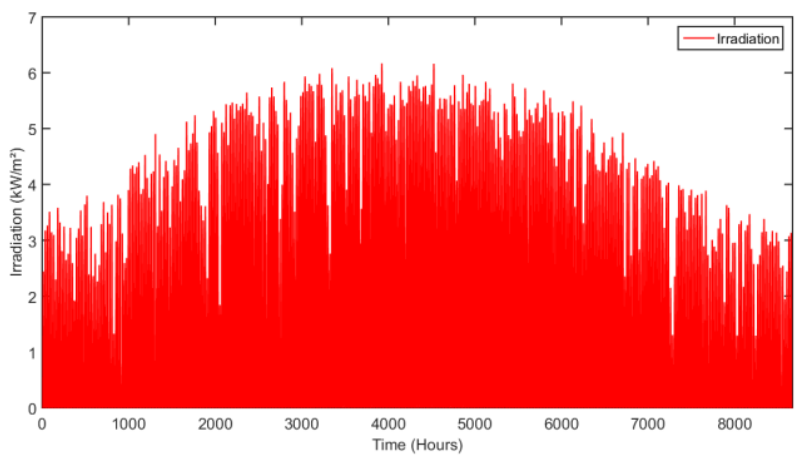




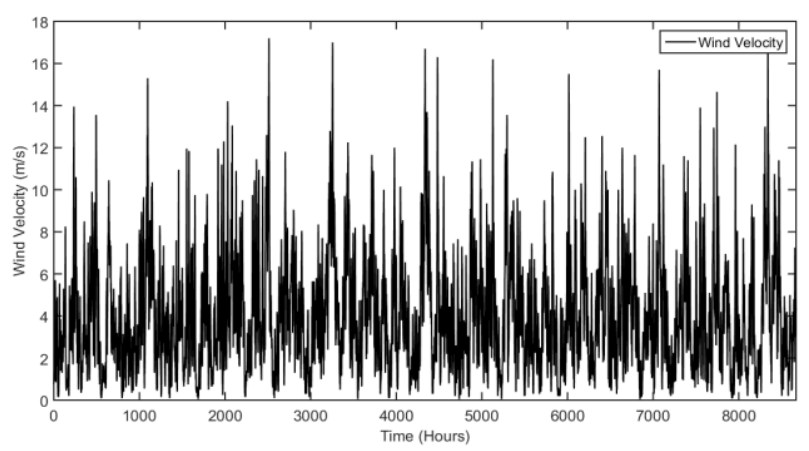

In IUR Rabat, the yearly average solar energy per day is $5.47 \mathrm{kWh} / \mathrm{m}^{2}$ (See Fig .1). The yearly average wind speed at $10 \mathrm{~m}$ hub height is $3.14 \mathrm{~m} / \mathrm{s}$. The hourly solar irradiation on a horizontal plane $\left(\mathrm{Wh} / \mathrm{m}^{2}\right)$, as well as and wind speed $(\mathrm{m} / \mathrm{s})$, is illustrated respectively in (Fig. 1).

\section{Result and discussion}

The proposed hybrid system configuration of HPWGS is composed of $10 \mathrm{kWp}$ of PV and $1 \mathrm{~kW}$ of the wind turbine. The dynamic simulation results of the HPWGS energy production and exchange are shown in the figure below (Fig.2 \& 3). The yearly average of energy production from a PV array is $11287.52 \mathrm{kWh}$, while the yearly average of energy production by the wind turbine is $1137.19 \mathrm{kWh}$. The optimized hybrid configuration can
Figure 1: Hourly and monthly weather data for UIR Rabat

ensure $12424.71 \mathrm{kWh} /$ Year, while the electrical load demand of the HPWGS is around $12154.5 \mathrm{kWh} / \mathrm{Year}$.

The energy output of the chosen period (April 01-05) and (January 02-06) is presented respectively in (Fig. 2) and (Fig. 3). The blue curve represents the hybrid energy production of the PV array and WT. The orange curve represents the nominal electrical load demand of an EVCP during a daytime. The excess of energy serves to charge the storage system (green curve). It may happen that the hybrid produced power doesn't cover the load demand at a specific period of the day. In that case, the battery can ensure the needed energy until its discharge (purple curve). When that happens, the system can connect to the grid in order to feed the loads (Fig. $2 \& 3$ ).

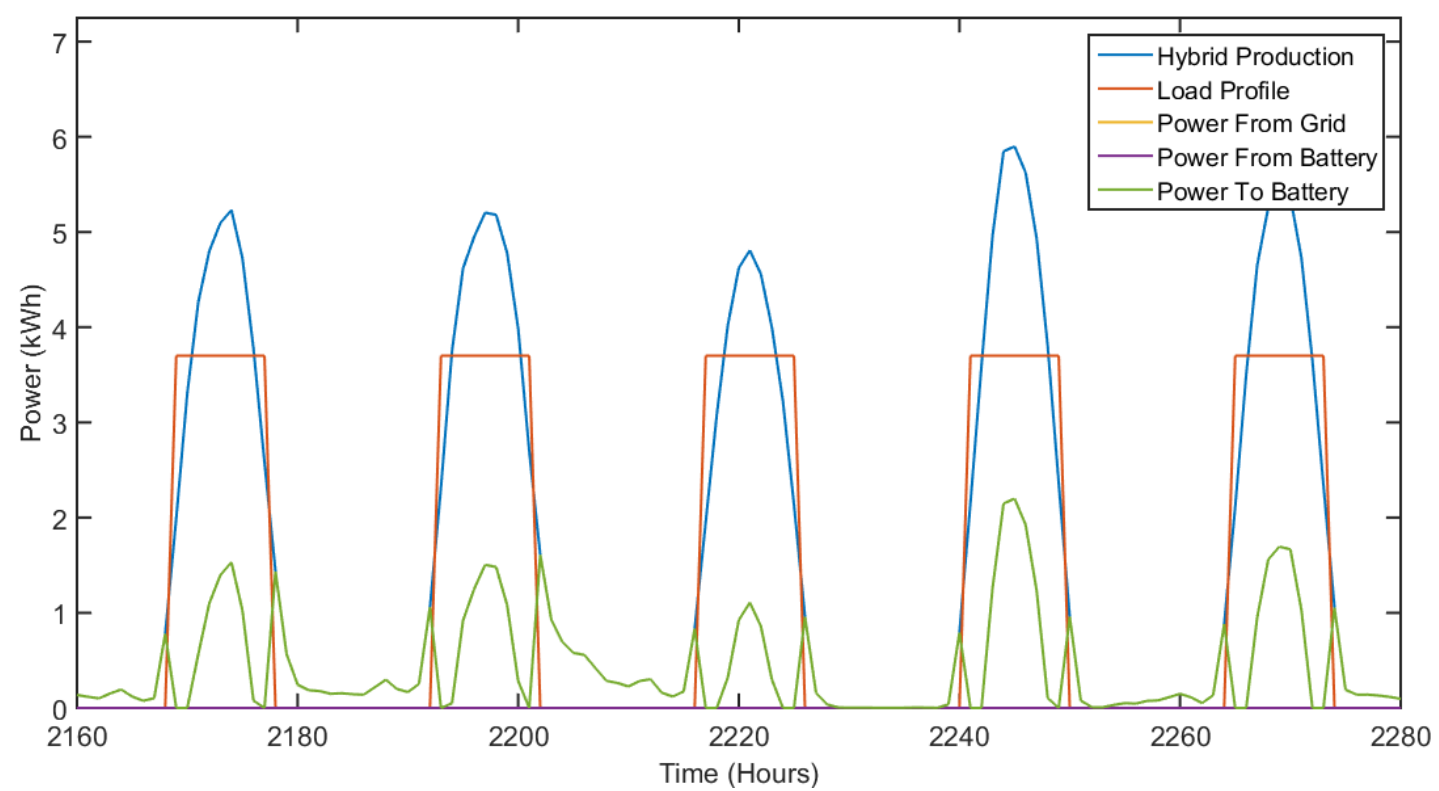

Figure 2: Dynamic simulation of the energy exchange (April 01-05) 


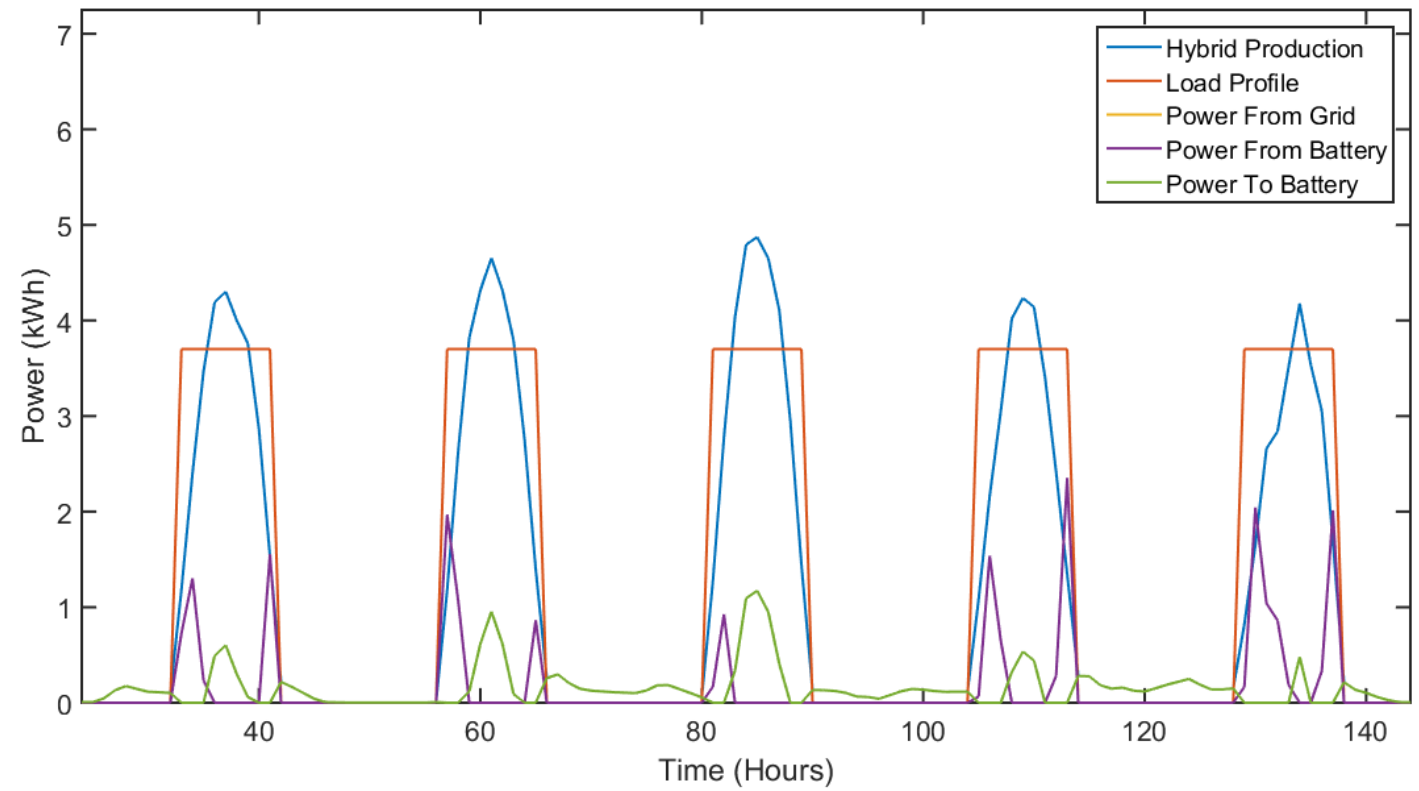

Figure3: Dynamic simulation of the energy exchange (January 02-06)

\section{Conclusions}

A modular EVCP using HPWGS are leading to a significant resolution of the low mobility distance caused by the low energy density of EV batteries and insufficient support infrastructure of the EVCP. The integration of Hybrid PV-Wind-Grid System. The Electric Vehicle Charging Platform is considered as a realistic renewable and sustainable solution aiming to power the electrical energy demand during the parking period. The EV charging process can be ensured totally or partially by HPWGS through the energy output of photovoltaic panels (PV) and wind turbine (WT). The excess of energy production after fully charged the EV battery is injected into the grid, the EVCP can be connected to the grid to charge the EV batteries when there is no sufficient energy output from the RES and no sufficient energy stocked at the EVCP batteries.

A simulation study has been conducted for the optimized configuration of HPWGS aiming to evaluate the longterm energy output, then to illustrate the energy exchange between the EVCP batteries, EV batteries and grid using the TRNSYS/Matlab program. The electrical energy will be provided from the renewable energy system installed on the upper surface of the covered parking surface. EVCP will ensure a sustainable gateway for transportation in the future with a direct utilization of the HPWGS.

\section{Acknowledgments}

The authors would like to express their appreciation to "IRESEN" by providing financial support to carry out this research under the project "Continued heating of bitumen storage by using high energy solar thermal collectors". We would like to emphasize that. We have not been able to complete this research without the joint support of all employees of the renewable energy laboratory and its hierarchical superior of the UIR (International University of Rabat). We take this opportunity to express our deep gratitude and greeting to M. LAKNIZI Azzeddine for his inspiring and invaluable advice and availability.

\section{References}

[1] Yilmaz M, Krein PT. Review of the Impact of Vehicle-to-Grid Technologies on Distribution Systems and Utility Interfaces. IEEE Trans Power Electron 2013;28:5673-89. doi:10.1109/TPEL.2012.2227500.

[2] Capasso C, Veneri O. Experimental study of a DC charging station for full electric and plug in hybrid vehicles. Appl Energy 2015;152:131-42. doi:10.1016/j.apenergy.2015.04.040.

[3] Birnie DP. Solar-to-vehicle (S2V) systems for powering commuters of the future. J Power Sources 2009;186:539-42. doi:10.1016/J.JPOWSOUR.2008.09.118.

[4] Nunes P, Farias T, Brito MC. Day charging electric vehicles with excess solar electricity for a sustainable energy system. Energy 2015;80:26374. doi:10.1016/j.energy.2014.11.069.

[5] Traube J, Lu F, Maksimovic D. Electric vehicle DC charger integrated within a photovoltaic power system. Conf Proc - IEEE Appl Power Electron Conf Expo - APEC 2012:352-8. doi:10.1109/APEC.2012.6165843.

[6] Chandra Mouli GR, Bauer P, Zeman M. Comparison of System Architecture and Converter Topology for a Solar Powered Electric Vehicle Charging Station. ECCE Asia 2015:1908-15. doi:10.1109/ICPE.2015.7168039.

[7] Anoune K, Bouya M, Ghazouani M, Astito A, Abdellah A Ben. Hybrid renewable energy system to maximize the electrical power 
production. 2016 Int. Renew. Sustain. Energy Conf., Marrakech, Morocco: 2016, p. 533-9. doi:10.1109/IRSEC.2016.7983992.

[8] Anoune K, Laknizi A, Bouya M, Astito A, Ben Abdellah A. Sizing a PV-Wind based hybrid system using deterministic approach. Energy Convers Manag 2018;169:137-48. doi:10.1016/j.enconman.2018.05.034.
[9] Anoune K, Bouya M, Astito A, Abdellah A Ben. Sizing methods and optimization techniques for PV-wind based hybrid renewable energy system: A review . Renew Sustain Energy Rev 2018;93:652-73. doi:10.1016/j.rser.2018.05.032.

[10] Nissan Motor. Nissan LEAF specifications. n.d.

[11] TRNSYS. http://www.trnsys.com/ n.d. 